International Journal of Child, Youth and Family Studies (2014) 5(2): 332-345

\title{
GENDER AND LANGUAGE: EXAMINING THE USE OF DIAGNOSTIC LANGUAGE IN THE DISCUSSION OF GENDER VARIANCE
}

\section{Walker}

\begin{abstract}
Gender is considered to be one of the major organizing principles in an individual's life; however, a unified understanding of what gender is and how gender identity is developed continues to spark debate and discussion for practitioners and academics. This literature review examines literature that discusses gender identity and development in order to explore the words, language, and terminology currently being used to discuss gender. Although the literature search generated articles which discussed a wide variety of issues relating to gender and gender identity development, a common theme throughout the literature was an absence of language that allows individuals to describe themselves outside heteronormative, binary ideals of gender without resorting to the use of the diagnostic categories and language to describe and explain gender variance.
\end{abstract}

Keywords: gender, gender identity, Gender Dysphoria, Gender Identity Disorder, language

M. Walker is a graduate student at the School of Child and Youth Care, University of Victoria, P.O. Box 1700, STN CSC, Victoria B.C., Canada, V8W 2 Y2.

E-mail: mattiew@uvic.ca 
Gender is considered to be one of the major organizing principles in an individual's life (Kaschak, 1992); however, a unified understanding of what gender is and how gender identity is developed continues to spark debate and discussion for practitioners and academics (e.g., Braun \& Wilkinson, 2005; Diamond \& Butterworth, 2008; Fausto-Sterling, 2012; Jeffreys, 2012; Langer \& Martin, 2004). Current understandings describe gender as a dynamic, interactive process between an individual and the social environment in which that individual exists (Bem 1993; Butler 1990; Fausto-Sterling, 2000, 2012). Although biological sex has long served as a looking glass through which individuals view decisions about how to think about and interact with others (Bem, 1993), there is a wide variance in how individuals embody gender in their own lives (Fausto-Sterling, 2000). Gender is considered to be a complex aspect of identity that one learns and develops throughout one's lifetime, and not necessarily representative of one's biological sex (Butler, 1990; de Beauvoir, 1953/1989; Fausto-Sterling, 2000).

Consistent definitions of what gender means, how gender identity is developed, and the role gender and gender identity plays in the lives of individuals are widely lacking throughout the literature (Carr, 2007; Diamond \& Butterworth, 2008). Diamond and Butterworth (2008) state the "difficulty in making sense of individuals with multiple identities, multiple subjectivities, and multiple social locations is manifested in the lack of language to describe such experiences” (p. 373). As such, language describing gender difference and gender variance typically falls into diagnostic categories that pathologize variance from prescribed social norms (Drescher, 2010). Nevertheless, scholars and activists continue to push towards a wider understanding of gender and identity (Devor, 2002; Drescher, 2010; Langer \& Martin, 2004; Wiseman \& Davidson, 2012), outside of dichotomous categories and beyond binary ideals, arguing that pathologizing gender-atypicality when there is a lack of consensus on genderappropriateness is untenable (Diamond \& Butterworth, 2008; Drescher, 2010).

This review initially examined the literature from the past 10 years that discusses gender identity, development, and language in order to explore what words, language, and terminology are currently being used to discuss gender. It is based on a literature search that was conducted using the keywords: "gender identity”; “development”; "language”; “identity formation”; and "narrative”. This search provided 46 peer-reviewed journal articles. From these, articles were selected based on publication date (published after 2003) and the use of gender as a term denoting a social role, resulting in 21 articles being selected for review. After noting commonly cited sources amongst the literature search results, additional sources (published prior to 2003) were reviewed in order to include significant research in the area of gender.

Although the literature search generated articles discussing a wide variety of issues relating to gender and gender identity development, a common theme was an absence of language allowing individuals to describe themselves outside heteronormative ${ }^{1}$, binary ideals of gender without resorting to the use of the diagnostic categories and language to describe and explain gender variance (Carr, 2007; Diamond \& Butterworth, 2008; Drescher, 2010). Despite

\footnotetext{
${ }^{1}$ Heteronormative refers to the social and cultural expectation that individuals are heterosexual and, therefore, fall into one of two distinct and opposite sex and gender categories (Oxford Dictionary, 2013).
} 
the recent removal of Gender Identity Disorder ${ }^{2}$ (GID) from the Diagnostic and Statistical Manual of Mental Disorders (DSM) (American Psychiatric Association, 2013a), the manual continues to include a similar diagnostic category of Gender Dysphoria (to be discussed later in this paper under the heading, Comparing Gender Identity Disorder and Gender Dysphoria). The debate about the necessity of the inclusion of this diagnosis in the DSM is ongoing with several scholars arguing for the removal of this diagnosis due to the parallels between the inclusion of gender variance diagnoses and the prior inclusion of homosexuality in the DSM (Drescher, 2010; Jeffreys, 2012; Langer \& Martin, 2004; Wiseman \& Davidson, 2012), despite recent amendments to the language of the diagnostic criteria (American Psychiatric Association, 2013b).

With recent media attention to the issues of acceptance of sexual diversity and trans*3 awareness (e.g., Canadian Broadcasting Corporation, 2013; Dudash, 2013; Fleischer, 2013; Sheldon \& Krop, 2013), the discussion of diversity is a central issue within such human services fields as Child and Youth Care (CYC). Child and Youth Care scholars and practitioners have suggested that "work in gender issues is not done" (de Finney, Little, Skott-Myre, \& Gharabaghi, 2012, p. 132). This literature review examines current understandings of gender and the use of diagnostic categories in the description of gender variance in order to further understand the complex role language plays in the development and understanding of gender identity.

\section{Defining Gender}

The term gender was introduced by feminist theorists to describe a social role and is considered to be a term connoting context (Bem, 1993; Butler, 1990; Drescher, 2010). Gender is a process of learned behaviour gleaned from an individual's life experience (Butler, 1990; de Beauvoir, 1953/1989; Gilbert \& Scher, 1999). Described as a dynamic, interactive process between an individual and the social environment in which the individual exists, gender is not a static trait within an individual (Butler, 1990). The realities of social life are products of language and meanings agreed upon. Butler (1990), reminds us that "to claim that gender is constructed is not to assert its illusoriness or artificiality” (p. 45), but to remind us that gender is an ongoing discursive practice. This relational or contextual point of view suggests that what a person is, or what gender is, is always relative to the constructed relations in which this is determined (Butler, 1990). "As a shifting and contextual phenomenon, gender does not denote a substantive being, but a relative point of convergence among culturally and historically specific sets of relations” (Butler, 1990, p. 14).

The categories of male and female are central to social thought, "entering virtually every domain of human experience and structuring human relationships . . . [g]ender categories serve to label, define and rank" (Hare-Mustin \& Mareck, 1990, p. 184). While cross-cultural studies

\footnotetext{
${ }^{2}$ Gender Identity Disorder was included in editions III and IV-TR of the DSM (Byne et al., 2012; American Psychiatric Association, 2000).

${ }^{3}$ Trans* "is an umbrella term that attempts to capture the complexity and diversity of gender identity and expression by those who transgress gender boundaries. The term trans* may encompass (but is not limited to) those who identify as transgender, genderqueer, trans, transsexual, androgynous, agender, bigender, two spirit, and gender nonconforming. The asterisk is used as a visible signifier of the diversity within trans* communities. Trans* people can be of any race, class, (dis)ability, faith, culture, sexual orientation, or citizenship status, and can have a vast variety of gender identities and expressions” (Trans* Awareness Project, n.d.).
} 
International Journal of Child, Youth and Family Studies (2014) 5(2): 332-345

have revealed a wide range in how gender is conceptualized, discussed, and embodied around the world (Fausto-Sterling, 2000), it appears that the "possession of a single sex [or gender] is a necessity in our social order” (Dreger, 1998, as cited in Fausto-Sterling, 2000, p. 42).

This literature review has identified that despite ongoing debate and discussion around the construct of gender (Braun \& Wilkinson, 2005; Carr, 2007; Diamond \& Butterworth, 2008; Fausto-Sterling, 2000), there appears to be limited understanding of how the language and narrative around gender impacts and influences gender identity development in children and youth. Drawing on ideas from Narrative Theory (e.g., White, 2007), language can be understood as a powerful tool in the construction of self-concept and identity. The words that individuals use to describe gender for themselves and for others can have an enormous impact on how individuals see both themselves and others, and on how they interact with the world around them (Derrida, 1995; Hansen, 2006). As language is arguably a system used to label and define, linguistic practices and social roles are delineated along a binary ideal of gender and sex (Barthes, 1979, as cited in Hare-Mustin \& Mareck, 1990). Wittig (1984) discusses how individuals cannot be signified within language without the mark of gender: An individual is either one gender or the other, one is either a woman or a man.

The difficulty in grasping the meaning of gender is further complicated by the pervasive cultural belief that gender differences are due to underlying biological differences, leading to conventional meanings of gender that typically focus on the difference between two distinct gender categories (Hare-Mustin \& Mareck, 1990). This leaves little or no opportunity for individuals to describe gender identities and experiences that may fall outside hegemonic, binary ideals of masculine and feminine, without being subjected to diagnoses (Carr, 2007; Wiseman \& Davidson, 2012).

\section{Gendered Bodies}

Despite ongoing discussion and debate around the constructs of sex and gender, gender identity continues to be "assumed to be predicated on the prior existence of dichotomously sexed bodies” (Braun \& Wilkinson, 2005, p. 509). In dismantling this idea, Fausto-Sterling (2000, 2012) has cited the wide variation in physical bodies and the culturally specific gendered behaviour deemed appropriate. Nevertheless, gender and sex continue to be used interchangeably in medical, academic, and colloquial contexts (Fausto-Sterling, 2000).

While many scholars contend for the acceptance of gender as separate from sex (e.g., Butler, 1990; Fausto-Sterling, 2000, 2012), several studies (e.g., Braun \& Wilkinson, 2005; Carr, 2007; Collier, Bos, \& Sandfort, 2013; Diamond \& Butterworth, 2008) have found complex links between gender, sexuality, and biological sex stating that an individual's physical features may be a determining factor in how they consider their own gender. While Braun and Wilkinson (2005) and Wilson et al. (2010) discuss the relationship between physical appearance (i.e., genitals) and a shared identification with a gender group, conversely, Paechter (2003) discusses the complex interplay of biological bodies with social performative roles. Paechter (2003) claims that although we may want to separate bodies from behaviours, bodies and behaviours remain connected: The body must be considered a medium from which gender is performed. 
International Journal of Child, Youth and Family Studies (2014) 5(2): 332-345

The idea of physical bodies and biology is intertwined with the idea of gender identity throughout much of the discussion of gender and gendered identity in the literature (e.g., Drescher, 2010; Fausto-Sterling, 2000; Wilson, 1998), particularly in articles that discuss the diagnosis of GID (Wiseman \& Davidson, 2012). The controversial link between gender identity and physical selves is cited throughout many articles (e.g., Drescher, 2010; Langer \& Martin, 2004; Wiseman \& Davidson, 2012) as the essential argument for the inclusion of GIDs in the DSM (American Psychiatric Association, 2013a). To facilitate medical intervention for individuals seeking surgery and/or hormone therapy in order to "align" their physical selves to their experienced gender (Drescher, 2010), the existence of a diagnostic label must be present (British Columbia Ministry of Health, 2013).

While many feminist, queer, and critical theorists work to deliberately displace biology, therefore opening the body to social and cultural shaping (Fausto-Sterling, 2000), Wilson (1998) suggests that we must develop a theory of mind and body, connecting an account of how the brain and biology work within cultural and social environments. As Fausto-Sterling (2000) examines in depth, not only is bodily sex malleable, existing on a continuum, but so, too, is our conceptualization of what sex and gender mean. Scientific narratives continue to transform in order to conform to the evolution of our cultural and social expectations of what it means to be normal and what it means to be deviant (Fausto-Sterling, 2000). "Bodies . . . only live within the productive constraints of certain highly gendered regulatory schemas” (Butler, as cited in FaustoSterling, 2000, p. 75). That it is to say, the physical body of an individual exists within a social world and is subject to social regulatory practices, categorizations, and expectations (FaustoSterling, 2000). Although some argue that there "is no gender identity behind the expression of gender; that identity is performatively constituted by the very 'expressions' that are said to be its results” (Nietzsche, 1969, as cited in Butler, 1990, p. 34), gender identity continues to be an important aspect of self-concept and an integral part of existing within a social world.

\section{Diagnosing Difference}

Wilson et al. (2010) identify gender and gender expression as core constructs that impact health and health promotion efforts; however, noted throughout the literature is a lack of language that describes gender and gender expressions that differ from hegemonic norms and an acknowledgment of using GID and Gender Dysphoria as a means of describing gender experiences that fall outside binary, heteronormative gender roles.

Researchers (e.g., Jeffreys, 2012; Wiseman \& Davidson, 2012) argue that using the medical model through assessment and diagnosis to "promote acceptance of gender difference perpetuates the use of binary gender discourse as well as associating gender difference with the stigma associated with mental illness” (Wiseman \& Davidson, 2012, p. 532). “Diagnosis, utilizing binary concepts of sex and gender ... provokes a dilemma for clinicians” working with gender-variant individuals (Wiseman \& Davidson, 2012, p. 532) as binary formulations of gender lead to etiological theories that use heteronormative standards to marginalize nonheterosexual, non-binary expressions of gender (Drescher, 2010). Nevertheless, individuals whose gender identities fall outside of binary norms experience high levels of stress, depression, self-harm behaviours, and other poor mental health outcomes (Drescher, 2010; Bandini et al., 2011). Receiving medical interventions to help with these negative experiences is stated as one 
International Journal of Child, Youth and Family Studies (2014) 5(2): 332-345

of the primary reasons for seeking a diagnosis of GID or Gender Dysphoria (Drescher, 2010; Wiseman \& Davidson, 2012).

\section{Diagnostic and Statistical Manual of Mental Disorders}

With the recent publication of the fifth edition of the Diagnostic and Statistical Manual of Mental Disorders (DSM-5), the American Psychiatric Association (2013b) released a statement justifying the controversial removal of GID from the manual and replacing it with a markedly similar Gender Dysphoria (Langer \& Martin, 2004; Wiseman \& Davidson, 2012), stating that "part of removing stigma is about choosing the right words" (American Psychiatric Association, 2013b). One of the key arguments against the continued presence of gender dysphoric diagnoses in the DSM is that it parallels the previous inclusion of homosexuality as a diagnosis in the past editions of the $D S M^{4}$ (Wiseman \& Davidson, 2012). At the root of this controversy is the lack of available language describing natural variance in social behaviour and identity expression (Carr, 2007; Diamond \& Butterworth, 2008; Drescher, 2010; Wiseman \& Davidson, 2012). With a large divide in theoretical and practical understandings of sex, gender, and sexuality (Fine, 2010), a widely used diagnostic manual - that is, the DSM-5 (American Psychiatric Association, 2013a) - is used as a determining voice in the categorization and understanding of what it means to be masculine, feminine, or any gender in a modern society.

Trans*, a generally accepted gender identity term amongst the queer ${ }^{5}$ communities (Trans* Awareness Project, n.d.), stems from the term transgender (Devor, 2002; Drescher, 2010). Despite the frequent colloquial use of trans* and transgender, neither word is present in any edition of the DSM. Nevertheless, individuals who identify as trans* and wish to receive medical interventions such as counselling, cross-sex hormones, gender reassignment surgery, or social and legal transition to the desired gender require a diagnosis of Gender Dysphoria (formerly GID) in British Columbia (American Psychiatric Association, 2013b; British Columbia Ministry of Health, 2013).

While the American Psychiatric Association (2013b) states that "persons experiencing gender dysphoria need a diagnostic term that protects their access to care and won't be used against them in social, occupational, or legal areas” (para. 8), researchers have identified consistent links between receiving a mental health diagnosis and social stigmatization (Wiseman \& Davidson, 2012). Research has shown that individuals who identify as trans* and/or have been diagnosed with GID or Gender Dysphoria experience high levels of mental health challenges for example: anxiety, body dissatisfaction, depression, and self-harm - as well as maltreatment and victimization (Bandini et al., 2011; Wiseman \& Davidson, 2012). Although the causal relationship between receiving a diagnosis of GID or Gender Dysphoria and the experience of maltreatment and poor mental health outcomes are inconclusive (Bandini et al., 2011), there is research which supports the view that receiving a mental health diagnosis leads to social stigmatization (Wiseman \& Davidson, 2012).

\footnotetext{
${ }^{4}$ Homosexuality was removed from the DSM in 1973 (Drescher, 2010).

${ }^{5}$ Queer is used in this context as an inclusive term acknowledging the diversity amongst the community of individuals identifying as lesbian, gay, bisexual, trans, questioning, asexual, and allies.
} 
International Journal of Child, Youth and Family Studies (2014) 5(2): 332-345

While many researchers (e.g., Drescher, 2010; Langer \& Martin, 2004; Wiseman \& Davidson, 2012) critique the continued inclusion of gender variance diagnoses (i.e., Gender Dysphoria) in the DSM-5, some research suggests that individuals may experience a sense of relief and/or certainty and acceptance of the gender identity with the diagnosis of Gender Dysphoria (or GID), as it allows individuals a means to describe and categorize their experiences (Drescher, 2010). Nevertheless, other researchers continue to critique these diagnoses for polarizing gender experiences into two categories and failing to allow for fluidity in the expression of gender (Jeffreys, 2012; Lafrance, 2005; Wiseman \& Davidson, 2012).

Jeffreys (2012) provides a critique of the medical interventions used as treatment for individuals diagnosed with GID, or Gender Dysphoria, arguing that individuals that are subjected to these practices can be seen as being forced into conforming to heteronormative standards of gender and sex. Jeffreys argues that, although these issues have been taken up as an issue of positive human rights, these practices should actually be seen as practices that violate human rights, especially when children and youth are the subjects of such interventions. Similar to arguments against the inclusion of GID (particularly GID in children) and Gender Dysphoria, administering treatment of these disorders based on the DSM-5 (American Psychiatric Association, 2013a) diagnostic categories can be seen as a means of preventing homosexuality and/or adult transsexualism (Drescher, 2007; Jeffreys, 2012; Mass 1990; Sedgwick; 1991).

\section{Comparing Gender Identity Disorder and Gender Dysphoria}

Although currently not utilized as a diagnosis, GID (American Psychiatric Association, 2013a) was "characterized by a strong and persistent identification with the opposite sex" (Bandini et al., 2011, p. 277). Despite continued discussion about the concepts of sex and gender, defined by Diamond and Butterworth (2008) as “orthogonal constructs” (p. 371), diagnoses, medical models, and researchers often use the terms gender and sex interchangeably (Diamond \& Butterworth, 2008). A notable confusion of the GID construct is the continued link to sex and biological bodies (Fausto-Sterling, 2000, 2012). If gender can be considered as solely a social role, then the discussion of physical appearance should be nullified; however, as the body can be considered a medium from which social roles are enacted and expressed (Paechter, 2003), the idea of body dissatisfaction, medical intervention, and the need for a diagnostic label become viable (Drescher, 2010; Jeffreys, 2012).

The American Psychiatric Association (2013b) has stated that “replacing 'disorder’ with 'dysphoria' in the diagnostic label is not only more appropriate and consistent with familiar clinical sexology terminology, it also removes the connotation that the patient is 'disordered'” (para. 3, quotes in original). Gender Dysphoria can be understood as a less stigmatizing diagnosis (American Psychiatric Association, 2013b). Despite changes to the language describing diagnostic categories, as already noted above, individuals who are perceived to be different are often victims of maltreatment and marginalization (Bandini et al., 2011; Collier et al., 2013). 
International Journal of Child, Youth and Family Studies (2014) 5(2): 332-345

\section{Marginalization and Victimization}

Perceived difference is often a risk factor for victimization and marginalization in social groups (Collier et al., 2013). Gender is a severely policed form of identity expression (Carr, 2007) and perceived or actual difference in gender expression has been explored as a risk factor for victimization, marginalization, and maltreatment. Although literature about the effects of victimization and maltreatment on gender identity development is limited (Bandini et al., 2011), several studies have examined the relationship between gender variant behaviour and victimization, marginalization, and maltreatment (e.g., Bandini et al., 2011; Collier et al., 2013).

Bandini et al. (2011) examined the relationship between diagnosed GID and childhood maltreatment. Although their findings demonstrated a positive correlation between experiencing maltreatment in childhood with GID, body dissatisfaction and poor mental health outcomes, these authors do not claim a causal link between childhood maltreatment and GID in adulthood. On the contrary, they suggest only that gender-variant behaviour may be a risk factor for experiencing childhood maltreatment. Similar findings were demonstrated in Collier et al.'s (2013) study on homophobic name-calling among secondary students. Collier and colleagues found that individuals who displayed gender non-conforming behaviour were common subjects of homophobic name-calling and peer victimization regardless of sexual orientation and suggest that victimization may be based on perceived difference.

Furthermore, Rieger, Linsenmeier, Gygax, Garcia, and Bailey (2010) suggests that gender non-conformity is often interpreted as evidence of minority sexual orientation, whether the subject of the victimization identifies this way or not. Despite common experiences of homophobic name-calling in trans* and gender non-conforming youth (Collier et al., 2013; Grossman \& D’Augelli, 2006; McGuire, Anderson, Toomey, \& Russell, 2010), it is unclear whether name-calling is meant to address the gender non-conforming behaviour, the perceived sexual orientation, or both (Collier et al., 2013).

Although difference and gender non-conforming behaviour are cited as possible risk factors for peer victimization and childhood maltreatment (Bandini et al., 2011; Collier et al., 2013), it is as yet unclear, in all probability because of a scarcity of research in this area, what the effects of victimization are on the development of gender identity (Bandini et al., 2011). Thus, Ewing Lee and Troop-Gordon (2011) found that some forms of peer victimization and rejection lead to increases in gender non-conforming behaviour, whereas, several other studies suggest that gender non-conforming behaviours cease in response to peer victimization (Pilkington \& D’Augelli, 1995; Wyss, 2004). These findings suggest a connection to the idea of social modelling and acceptance within a social group. Paechter (2003) explores the idea that gender identity is developed through a process of modelling and social learning. Paechter presents a model of socially acceptable gender norms being continually enforced through individuals seeking recognition as "legitimate" members of a social group. As individuals are marginalized, victimized, and/or ostracized based on perceived or actual difference (Bandini et al., 2011; Collier et al., 2013), they may engage in a process of active modification of gender expression, gender role assumption, and personal conceptions of gender identity (Moore, 2003; Paechter, 2003). Moore (2003) draws on this idea in a study conducted at a summer camp: By observing how children "policed" and "enforced" acceptable gender norms in the context of a summer 
International Journal of Child, Youth and Family Studies (2014) 5(2): 332-345

camp, Moore explored the ideas of gender boundaries, gendered articulations, and gender separation.

Braun and Wilkinson (2005) argue that "a dichotomous [gender] system is sustained not only through cultural representations and medical models and procedures, but also through everyday taken-for-granted talk and practices” (p. 510). Drawing on current themes throughout the literature, it is suggested that exploring how language is used to describe gender experiences and identities could promote a greater awareness of issues surrounding gender-based violence and gender diversity (Mallon \& DeCrescenzo, 2006) and may also promote gender identity exploration for individuals (Diamond \& Butterworth, 2008).

\section{Diversity of Experience}

Throughout the literature reviewed, it was identified that despite a lack of language to describe gender variance, there is great diversity in the experience of gender in individuals' lives (Fausto-Sterling, 2000, 2012; Mallon \& DeCrescenzo, 2006). Scholars, such as Diamond and Butterworth (2008), suggest using a theory of intersectionality ${ }^{6}$ in the conceptualization of gender and gender experiences in order to acknowledge the fluidity and multiplicity in gender identity and the inherent change processes that occur throughout identity formation. As Kimmel (2008) states, many of the differences between genders that we observe in individuals and use to categorize them everyday are not gender differences but rather are differences that are the result of being in different social locations. Fausto-Sterling (2012) suggests that understanding the complex pathways that lead to variation in human identity development could provide a greater tolerance of variability among individuals.

While research suggests a need for language and terminology that describes gender and gender identities outside of binary categories (Wiseman \& Davidson, 2012), some scholars (e.g., Diamond \& Butterworth, 2008; Mallon \& DeCrescenzo, 2006) suggest that having new language to describe alternate gender expression may lead to further categorization and labelling of individuals, ignoring the fluid nature of gender and gender expression. The idea of one "true gendered self” is debatable (Lafrance, 2005; Wiseman \& Davidson, 2012), with many researchers suggesting that gender can be a fluid aspect of identity, which may change with an individual's changing social roles and expectations (Diamond \& Butterworth, 2008).

\section{Future Directions for Practice and Research}

In the Competencies for Professional Child and Youth Care Practitioners (Association for Child and Youth Care Practice, 2010), actively promoting respect for cultural and human diversity is considered a key element to professional practice within the Child and Youth Care field. Gender identity is an area of diversity that continues to be explored and examined in many helping fields, including Child and Youth Care (de Finney et al., 2012). Despite much research and academic discussion in this area, as noted in this literature review, heteronormative, binary ideals of gender continue to be a dominant force in the understanding and interpretation of

\footnotetext{
${ }^{6}$ Intersectionality is defined as the study of the intersection of multiple aspects of identity, usually related to marginalization, to form a unique experience of oppression, discrimination, and/or marginalization (Diamond \& Butterworth, 2008)
} 
International Journal of Child, Youth and Family Studies (2014) 5(2): 332-345

gender in the helping field (Mallon \& DeCrescenzo, 2006). There is an identified need for new language and terminology that can describe gender experiences outside of a limiting binary framework (Wiseman \& Davidson, 2012).

This review of the current literature suggests a need for research exploring the relationship between gender variant behaviour and childhood maltreatment as well as adolescent and adult marginalization and victimization (Bandini et al., 2011). Further research is needed to explore the link between gender identity formation and available language, as some researchers suggest (e.g., Diamond \& Butterworth, 2008) that access to language describing gender as a fluid identity trait may lead individuals to further explore their gender identities and expressions. With researchers and scholars still debating the use of diagnostic categories in the description of gender variant behaviour, more research is needed to explore the causal relationship between receiving a mental health diagnosis, stigmatization, and poor mental health outcomes (Diamond \& Butterworth, 2008; Drescher, 2010; Wiseman \& Davidson, 2012). Upon review of the literature, a scarcity of research addressing practical applications and suggestions for promoting a wider understanding of gender and identity was noted. Many scholars call for language that describes gender and gender variance outside of dichotomous categories and beyond binary ideals (Devor, 2002; Drescher, 2010; Langer \& Martin, 2004; Wiseman \& Davidson, 2012), which would allow individuals who experience gender variance to describe themselves outside of diagnostic categories.

By continuing to explore how language shapes and informs gender identity development, practitioners in Child and Youth Care, and other allied professions, will be better prepared to support children and youth in the development of their own identities (Mallon \& DeCrescenzo, 2006). Utilization of a lexicon that describes gender outside of binary, heteronormative categories will promote diversity awareness and support community appreciation for difference (Mallon \& DeCrescenzo, 2006). By gaining a deeper understanding of how language impacts and informs gender identity development, practitioners in Child and Youth Care and other allied professions can best support individuals through navigating the gender identity formation process without labelling or limiting their experiences. 
International Journal of Child, Youth and Family Studies (2014) 5(2): 332-345

\section{References}

American Psychiatric Association. (2000). Diagnostic and statistical manual of mental disorders (4th ed. rev.). Washington D.C.: American Psychiatric Association.

American Psychiatric Association. (2013a). Diagnostic and statistical manual of mental disorders (5th ed.). Arlington, VA: American Psychiatric Publishing.

American Psychiatric Association. (2013b). Gender Dysphoria fact sheet. Retrieved October 2013 from: http://www.dsm5.org/Documents/Gender\%20Dysphoria \%20Fact\%20Sheet.pdf

Association for Child and Youth Care Practice. (2010). Competencies for professional child \& youth work practitioners (revised 2010). (Originally published: Child \& Youth Work, 17, 16-29).

Bandini, E., Fisher, A. D., Ricca, V., Ristori, J., Meriggiola, M. C., Jannini, E. A., et al. (2011). Childhood maltreatment in subjects with male-to-female gender identity disorder. International Journal of Impotence Research, 23(6), 276-285. http://dx.doi.org/10.1038/ijir.2011.39

Bem, S. L. (1993). The lenses of gender: Transforming the debate on sexual inequality. Binghamton, NY: Vail-Ballou Press.

Braun, V., \& Wilkinson, S. (2005). Vagina equals woman? On genitals and gendered identity. Women's Studies International Forum, 28(6), 509-522. http://x.doi.org/10.1016/j.wsif.2005.09.007

British Columbia Ministry of Health. (2013). Sex reassignment services in British Columbia: New standards of care. Retrieved December 2013 from: http:// www.health.gov.bc.ca/msp/infoprac/physnews/srs-in-british-columbia.pdf

Butler, J. (1990). Gender trouble: Feminism and the subversion of identity. New York: Routledge

Byne, W., Bradley, S., Coleman, E., Eyler, A. E., Green, R., Menvielle, E. J., et al. (2012). Report of the American Psychiatric Association task force on treatment of Gender Identity Disorder [data supplement]. Archives of Sexual Behavior, 41(4), 756-796.

Canadian Broadcasting Corporation. (2013, March 26). Battle over marriage equality in America goes before U.S Supreme Court. George Stromboulopoulos Tonight. Retrieved December 2013 from http://www.cbc.ca/strombo/news/battle-over-marriage-equality-in-americagoes-before-us-supreme-court.html

Carr, C. L. (2007). Where have all the tomboys gone? Women's accounts of gender in adolescence. Sex Roles, 56(7/8), 439-448. http://dx.doi.org/10.1007/s11199-007-9183-7 
International Journal of Child, Youth and Family Studies (2014) 5(2): 332-345

Collier, K. L., Bos, H. M. W., \& Sandfort, T. G. M. (2013). Homophobic name-calling among secondary school students and its implication for mental health. Journal of Youth and Adolescence, 42(3), 363-375. http://dx.doi.org/10.1007/s10964-012-9823-2

de Beauvoir, S. (1989). The second sex. New York: Vintage Books. (Original work published 1953)

de Finney, S., Little, J. N .C., Skott-Myhre, H., \& Gharabaghi, K. (2012). Roundtable: Conversations on conversing in child and youth care. International Journal of Child, Youth and Family Studies, 3(2/3), 128-145.

Derrida, J. (1995). The play substitution. In W. Anderson (Ed.), The truth about the truth: De-confusing and re-constructing the postmodern world (pp. 86-95). New York: G. P. Putnam \& Sons.

Devor, H. (2002). Who are "we”? Where sexual orientation meets gender identity. Journal of Gay \& Lesbian Psychotherapy, 6(2), 5-21. http://dx.doi.org/10.1300/j236v06n02_02

Diamond, L. M., \& Butterworth, M. (2008). Questioning gender and sexual identity: Dynamic links over time. Sex Roles, 59(5/6), 365-376. http:/dx.doi.org/10.1007/s11199-008-9425-3

Drescher, J. (2010). Queer diagnoses: Parallels and contrasts in the history of homosexuality, gender variance, and the Diagnostic and Statistical Manual. Archives of Sexual Behavior, 39(2), 427-460. http://dx.doi.org/10.1007/s10508-009-9531-5

Dudash, A. (2013). “Orange is the new black” star Laverne Cox visits UNC-Chapel Hill. Retrieved December 2013 from http://www.heraldsun.com/news/x2082482937/-Orangeis-the-New-Black-star-Laverne-Cox-visits-UNC-Chapel-Hill

Ewing Lee, E. A., \& Troop-Gordon, W. (2011). Peer socialization of masculinity and femininity: Differential effects of overt and relational forms of peer victimization. The British Journal of Developmental Psychology, 29(2), 197-213. http:/dx.doi.org/10.1111/j.2044-835x.2010.02022.x

Fausto-Sterling, A. (2000). Sexing the body: Gender politics and the construction of sexuality. New York: Basic Books.

Fausto-Sterling, A. (2012). The dynamic development of gender variability. Journal of Homosexuality, 59(3), 398-421. http://dx.doi.org/10.1080/00918369.2012.653310

Fine, C. (2010). Delusions of gender: How our minds, society, and neurosexism create difference. New York: W.W. Norton \& Company, Inc.

Fleischer, M. (2013). Two transgender women killed-so why can't this city call them hate crimes? Take Part. Retrieved December 2013 from http:/www.takepart.com/article/ 2013/12/12/state-transgender-rights-movement?cmpid=tp-ptnr-upworthy 
International Journal of Child, Youth and Family Studies (2014) 5(2): 332-345

Gilbert, L., \& Scher, M. (1999). Gender and sex in counseling and psychotherapy. Boston: Allyn and Bacon.

Grossman, A. H., \& D’Augelli, A. R. (2006). Transgender youth: Invisible and vulnerable. Journal of Homosexuality, 51(1), 111-128. http://dx.doi.org/10.1300/j082v51n01_06

Hansen, J. T. (2006). Counselling theories within a postmodernist epistemology: New roles for theories in counselling practice. Journal of Counselling and Development, 80(Summer), 291-297. http://dx.doi.org/10.1002/j.1556-6678.2006.tb00408.x

Hare-Mustin, R. T., \& Mareck, J. (Eds). (1990). Making a difference: Psychology and the construction of gender. New Haven, CT: Yale University Press.

Jeffreys, S. (2012). The transgendering of children: Gender eugenics. Women's Studies International Forum, 35(5), 384-393. http://dx.doi.org/10.1016/j.wsif.2012.07.001

Kashack, E. (1992). Engendered lives. New York: Basic Books.

Kimmel, M. S. (2008). The gendered society (3rd ed.). New York: Oxford University Press.

Lafrance, M. (2005, April). Speaking Sex: Foucault and the case of transsexual embodiment. Presentation given at Clinical Analogies-Thinking Embodied Subjectivity Across Disciplines, Lancaster University, Lancashire, UK.

Langer, S. J., \& Martin, J. I. (2004). How dresses can make you mentally ill: Examining gender identity disorder in children. Child and Adolescent Social Work Journal, 21(1), 5-23. http://dx.doi.org/10.1023/b:casw.0000012346.80025.f7

Mallon, G. P., \& DeCrescenzo, T. (2006). Transgender children and youth: A child welfare practice perspective. Child Welfare, 85(2), 215-241.

Mass, L. (1990). “Sissyness” as metaphor: A conversation with Richard Green. In L. Mass (Ed.), Homosexuality and sexuality: Dialogues of the sexual revolution (Vol. 1, pp. 213-222). New York: Harrington Park Press.

McGuire, J. K., Anderson, C. R., Toomey, R. B., \& Russell, S. T. (2010). School climate for transgender youth: A mixed method investigation of student experiences and school responses. Journal of Youth and Adolescence, 39(10), 1175-1188. http://dx.doi.org/10.1007/s10964-010-9540-7

Moore, V. A. (2003). Race, risk, and the emergence of gender boundaries: Kids crossing boundaries in summer camps. Qualitative Sociology, 26(2), 173-198.

Oxford Dictionary. (2013). Retrieved December 2013 from: http://www.oxforddictionaries.com/definition/english/heteronormative

Paechter, C. (2003). Learning masculinities and femininities: Power/knowledge and legitimate peripheral participation. Women’s Studies International Forum, 26(6), 541-552. http://dx.doi.org/10.1016/j.wsif.2003.09.008 
International Journal of Child, Youth and Family Studies (2014) 5(2): 332-345

Pilkington, N. W., \& D’Augelli, A. R. (1995). Victimization of lesbian, gay, and bisexual youth in community settings. Journal of Community Psychology, 23(1), 34-56.

http://dx.doi.org/10.1002/1520-6629(199501)23:1\%3C34::aid-jcop2290230105\%3E3.0.co;2-n

Rieger, G., Linsenmeier, J., Gygax, L., Garcia, S., \& Bailey, J. (2010). Dissecting “Gaydar”: Accuracy and the role of masculinity-femininity. Archives of Sexual Behavior, 39(1), 124-140. http://dx.doi.org/10.1007/s10508-008-9405-2

Sedgwick, E. (1991). How to bring your kids up gay. Social Text, 9, 18-27. http://dx.doi.org/10.2307/466296

Sheldon, M., \& Krop, J. (2013, December 7). 10-year-old transgender child fights to have gender removed from birth certificate [video file]. Global News. Retrieved December 2013 from http://globalnews.ca/news/1008919/10-year-old-transgender-child-fights-to-havegender-removed-from-birth-certificate/

Trans* Awareness Project. (n.d.). What is Trans*? Retrieved December 2013 from http://www.transawareness.org/what-is-trans.html

White, M. (2007). Maps of narrative practice. New York: W.W. Norton and Company.

Wilson, E. (1998). Neural geographies: Feminism and the microstructure of cognition. New York: Routledge.

Wilson, B. D. M., Harper, G. W., Hidalgo, M. A., Jamil, O. B., Torres, R. S., \& Fernandez, I. (2010). Negotiating dominant masculinity ideology: Strategies used by gay, bisexual and questioning male adolescents. American Journal of Community Psychology, 45(1/2), 169-185. http://dx.doi.org/10.1007/s10464-009-9291-3

Wiseman, M., \& Davidson, S. (2012). Problems with binary gender discourse: Using context to promote flexibility and connection in gender identity. Clinical Child Psychology and Psychiatry, 17(4), 528-538. http://dx.doi.org/10.1177/1359104511424991

Wittig, M. (1984). The mark of gender. Feminist Issues, 5(2), 3-12.

Wyss, S. E. (2004). “This was my hell”: The violence experienced by gender non-conforming youth in U.S. high schools. International Journal of Qualitative Studies in Education, 17(5), 709-730. http://dx.doi.org/10.1080/0951839042000253676 